\title{
Experimental investigation on the effect of mixed acids etched nickel foam electrode on performance of an alkaline direct ethanol fuel cell
}

\author{
Jiajia Zhang ${ }^{l, 2}$, Weiqi Zhang ${ }^{1}$, Lei Xing ${ }^{3}$, Huaneng $\mathrm{Su}^{l}$, and Qian $X u^{l, *}$ \\ ${ }^{1}$ Institute for Energy Research, Jiangsu University, 212013 Zhen jiang, China \\ ${ }^{2}$ School of Energy and Power Engineering, Jiangsu U niversity, 212013 Zhen jiang, China \\ 3 Institute of Green Chemistry and Chemical Technology, Jiangsu University, 212013 Zhenjiang, China
}

\begin{abstract}
The three-dimensional porous materials represented by nickel foam have broad application prospects in the fuel cell field due to their excellent physical properties (high conductivity, high porosity and high specific surface area, etc.). However, the smooth nickel foam skel eton not only limits the loadable amount of active materials, but also reduces the utilization efficiency of loaded active materials. Therefore, increasing the roughness of the nickel foam skeleton to improve the utilization of active materials has farreaching significance for the practical application. In this paper, we used mixed acids solution to etch the nickel foam and investigated the effect of etched nickel foam electrode on the performance of an alkaline direct ethanol fuel cell. It was found that mixed acids etching treatment can significantly improve the roughness of nickel foam skeleton and had a great influence on the ethanol oxidation half-reaction (EOR), while the effect on the single cell performance can negligible. Therefore, we believe that the pretreatment method of nickel foam has little effect on the performance of high loading actual electrode.
\end{abstract}

\section{Introduction}

In the era of energy development and revolution, it is a common goal of the international community to vigorously develop clean energy. Alkaline direct ethanol fuel cells (ADEFC), as a green and high-efficiency electrochemical energy conversion device that can directly convert chemical energy in ethanol and oxygen into electrical energy, have received extensive attention from researchers in recent years [1-4]. In the preparation of the anode electrode of the ADEFC, a threedimensional porous material represented by nickel foam can be used as a support material. Due to its excellent physical properties (high conductivity, high porosity and high specific surface area, etc.), nickel foam has broad application prospects in the fuel cell field [5]. However, the smooth nickel foam skeleton not only limits the loadable amount of active materials, but also reduces their utilization. Therefore, increasing the roughness of the nickel foam skeleton to improve the utilization of active materials has far-reaching significance for the practical application of nickel foam.

Since the surface of nickel metal can easily form inert oxide layer or hydroxide layer in a humid environment, it is usually necessary to clean the nickel foam with acid before use. As a conventional treatment solution, hydrochloric acid $(\mathrm{HCl})$ is widely used in the literature on nickel foam. However, $\mathrm{HCl}$ acid treatment can only remove the oxide layer on the nickel foam surface and expose the metallic nickel. It cannot increase the nickel foam roughness, and the skeleton is still smooth after treatment, which can also be confirmed by observing the SEM image of the previous paper [6-8]. Some researchers proposed to use mixed acids to roughen the nickel foam surface [9-10], and found that when the nickel foam is immersed in a mixed solution of a variety of strong acids (30 wt $\% \mathrm{HNO}_{3}, 10 \mathrm{wt} \% \mathrm{H}_{2} \mathrm{SO}_{4}$, $10 \mathrm{wt} \% \mathrm{H}_{3} \mathrm{PO}_{4}$ and $50 \mathrm{wt} \%$ glacial $\mathrm{CH}_{3} \mathrm{COOH}$ ) for a short period of time (less than 1 minute), many small pores will be formed on the skeleton, which is due to the chemical reaction between a large amount of free hydrogen ions in the mixed acids and metallic nickel. The generation of these small pores can increase the specific surface area of the nickel foam. When the active material is loaded, the area of the small pores can be used, thereby increasing the utilization rate of the catalyst.

Zhang et al. [10] explored the half-cell test of nickel foam electrode etched by mixed acids, but there is little research on the single cell. We know that due to many influencing factors when the cell is actually working, there is often a big difference between the ideal half-cell test and the full-cell performance. Therefore, in this paper we used mixed acids solution to etch the nickel foam and investigated the effect of etched nickel foam electrode on the performance of alkaline direct ethanol fuel cells.

\section{Experimental}

* Corresponding author: xuqian@ujs.edu.cn 


\subsection{Pretreatment of nickel foam}

First, the raw nickel foam was soaked in acetone and ultrasonicated for 20 minutes to remove the surface oil. Then, immersed in $1 \mathrm{M} \mathrm{HCl}$ solution and sonicated for 25 minutes; and the nickel foam used for the comparison test was immersed in the mixed acids solution $(30 \mathrm{wt} \%$ $\mathrm{HNO}_{3}, 10 \mathrm{wt} \% \mathrm{H}_{2} \mathrm{SO}_{4}, 10 \mathrm{wt} \% \mathrm{H}_{3} \mathrm{PO}_{4}$ and $50 \mathrm{wt} \%$ glacial $\mathrm{CH}_{3} \mathrm{COOH}$ ) for 10 seconds. Finally, use deionized water to clean the nickel foam.

\subsection{Preparation of nickel foam electrode}

The nickel foam was cut into a size of $1 \mathrm{~cm} * 2 \mathrm{~cm}$, dropped $50 \mu \mathrm{L}$ of $15 \mathrm{mM} \mathrm{Na}_{2} \mathrm{PdCl}_{4}$ solution on the surface, and then added $50 \mu \mathrm{L}$ of a mixed solution of 5 $\mathrm{mM} \mathrm{NaBH}_{4}$ and $2.5 \mathrm{mM} \mathrm{NaOH}$, and deposited $\mathrm{Pd}$ on the nickel foam surface by chemical reduction $[6,11]$. The deposition area of $\mathrm{Pd}$ was $1 \mathrm{~cm} * 1 \mathrm{~cm}$, and the upper 1 $\mathrm{cm} * 1 \mathrm{~cm}$ was the part of the working electrode used to collect current during the half-cell test. Then, the nickel foam electrode was dried under an infrared lamp for 10 minutes.

\subsection{EOR half-cell and single cell test}

The nickel foam electrode was used as the working electrode, the platinum mesh was used as the counter electrode, and the saturated calomel electrode (SCE) was used as the reference electrode. In the $1 \mathrm{M} \mathrm{KOH}$ solution saturated with $\mathrm{N}_{2}$, the ECSA was measured in the range of -1.0 to $0.2 \mathrm{~V}$ using the cyclic voltammetry of the electrochemical workstation with a scanning speed of 50 $\mathrm{mV} / \mathrm{s}$. In a mixed solution of $1 \mathrm{M} \mathrm{KOH}$ and $1 \mathrm{M} \mathrm{EtOH}$ saturated with $\mathrm{N}_{2}$, the EOR was measured in the range of $-1.0 \mathrm{~V}$ to $0.2 \mathrm{~V}$ using a scanning speed of $50 \mathrm{mV} / \mathrm{s}$.

Single cell performance was measured in a homemade MEA composed of a nickel foam anode, a Nafion 212 membrane, and a commercial carbon paper cathode [12-13]. On the anode used the above-mentioned electrode preparation method to load $\mathrm{Pd}$ catalyst on nickel foam surface, and the Pd loading was $1 \mathrm{mg} / \mathrm{cm}^{2}$, which was determined by weighing the electrode weight before and after. Carbon paper was used as diffusion layer in commercial cathode, with a Pt loading of 2 $\mathrm{mg} / \mathrm{cm}^{2}$. In this experiment, we used Nafion membrane to conduct $\mathrm{K}^{+}$to complete the internal circuit, and researchers have verified the feasibility of this method [14-15]. In order to enhance $\mathrm{K}^{+}$ion conduction ability, Nafion membrane needed to be soaked in $3 \mathrm{M} \mathrm{KOH}$ solution for 24 hours before use [12-13].

\section{Results and discussion}
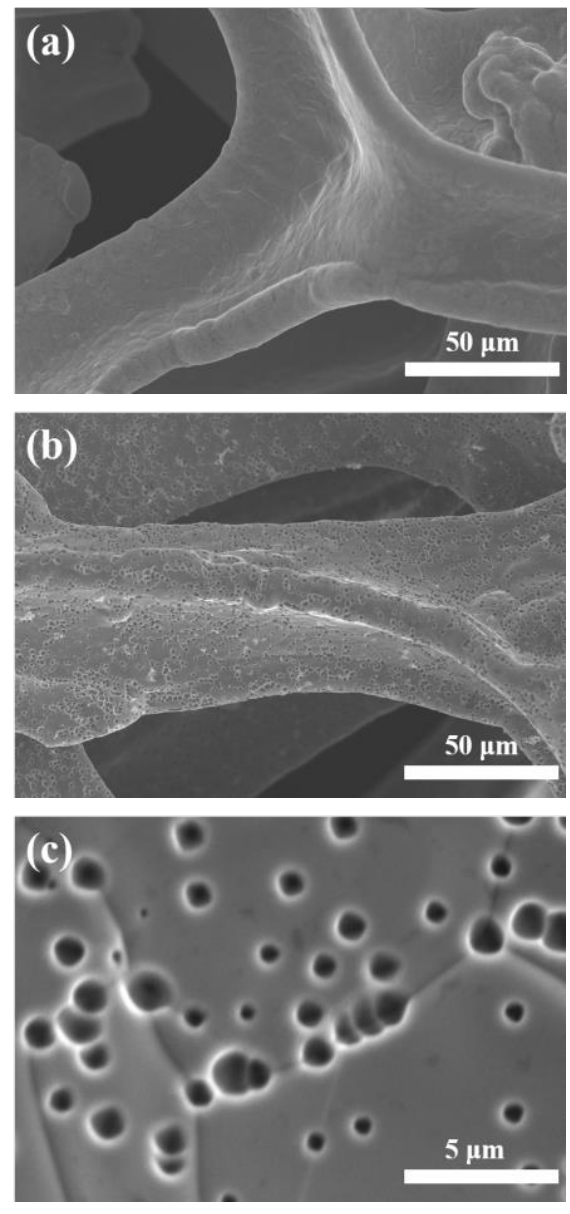

Fig. 1. (a) the nickel foam after $\mathrm{HCl}$ immersion treatment; (b) the nickel foam after mixed acid immersion treatment; and (c) the enlarged view of (b).

The SEM image of the nickel foam skeleton treated with $\mathrm{HCl}$ and mixed acids separately was shown in Fig. 1. It can be found in Fig. 1 (a) that the skeleton remained smooth after $\mathrm{HCl}$ treatment, which indicated that the conventional $\mathrm{HCl}$ treatment could only remove the surface oxide layer, while it was difficult to increase the surface roughness of nickel foam. The possible reason is that the amount of free hydrogen ions in the conventional $1 \mathrm{M} \mathrm{HCl}$ solution are not enough to etch the metal skeleton.

From Fig. 1 (b) and 1 (c) can be observed that the nickel foam surface treated with mixed acids had many small holes with a diameter of 1 micron, which should be caused by the corrosion effect of a large number of free $\mathrm{H}^{+}$in the mixed strong acids on the nickel foam skeleton.

Because of the strong acidity of the mixed acid solution, as the immersion time of nickel foam was extended, the skeleton would gradually soften and the three-dimensional structure would begin to collapse. When the nickel foam was immersed for more than 1 minute, the nickel foam would be completely corroded into nickel powder and could not be used. Therefore, in our experiment, we controlled the soaking time at 10 seconds. On account of the short soaking time, only 10 seconds, this could achieve the goal of making holes in the skeleton and improving the roughness of the skeleton 
without causing damage to the three-dimensional network structure of the nickel foam.

Compared with previous work, we found that the SEM images are consistent, which also reflects the correctness of the experimental operation [10].
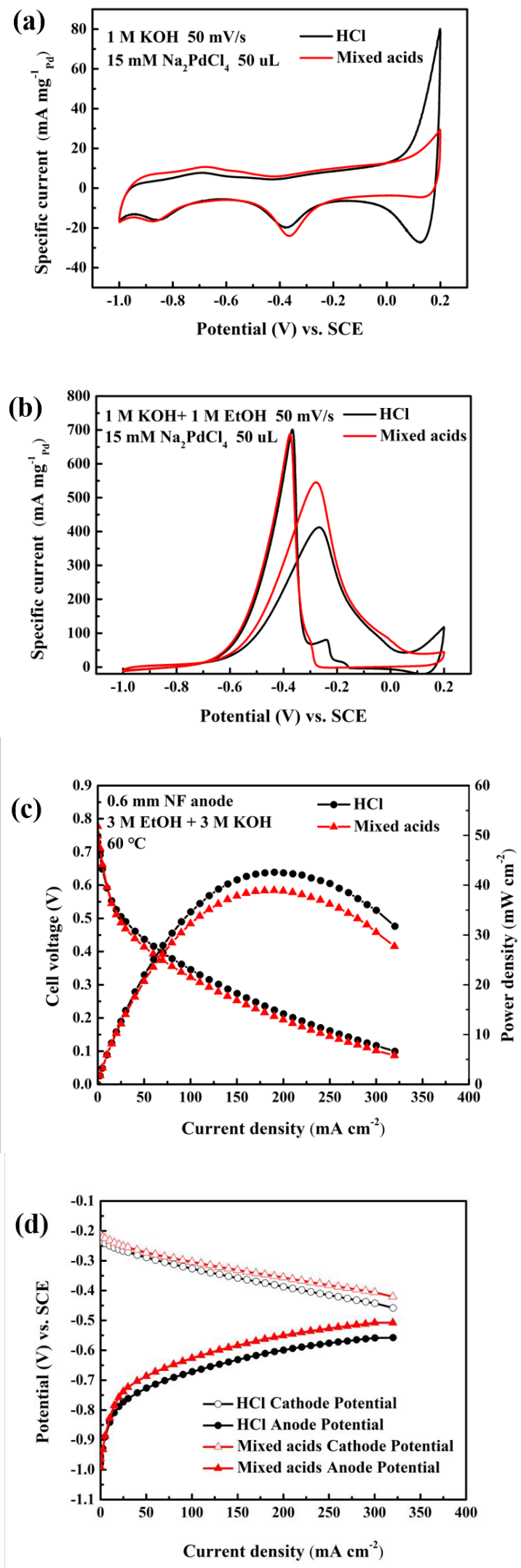

Fig. 2. (a) the CV measured in $1 \mathrm{M} \mathrm{KOH}$ solution; (b) the $\mathrm{CV}$ measured in $1 \mathrm{M} \mathrm{KOH}$ and $1 \mathrm{M} \mathrm{EtOH}$ solution; (c) the battery performance test; (d) using SCE as a reference electrode to separate cell voltage into independent anode and cathode potentials.

Fig. 2 (a) showed the electrochemically surface area (ECSA) of two kinds of acid-treated nickel foams loaded with the same content of Pd catalyst measured under the ideal environment of the three-electrode system [6]. By performing $\mathrm{CV}$ scanning in $1 \mathrm{M} \mathrm{KOH}$ solution, it can be observed that there was a reduction peak of $\mathrm{PdO}$ around $-0.4 \mathrm{~V}$; then by integrating the area of this reduction peak, the ECSA of the Pd catalyst can be obtained. The larger the ECSA, the more active sites exposed by Pd catalyst, which can improve the performance of EOR [16].

By observing the reduction peak of $\mathrm{PdO}$ at $-0.4 \mathrm{~V}$ (vs. $\mathrm{SCE}$ ), it can be found that the ECSA of Pd supported by nickel foam after mixed acid treatment was larger than that treated by $\mathrm{HCl}$. It was calculated that the ECSA treated with $\mathrm{HCl}$ and the mixed acids were $6.7 \mathrm{~m}^{2} / \mathrm{g}$, and $8.5 \mathrm{~m}^{2} / \mathrm{g}$, respectively, with an increase of $27 \%$. The reason for the increase was attributed to the many small pores with a diameter of 1 micron in the skeleton after the mixed acid etching, nano-sized Pd catalyst particles could be filled into the pores, which made the micro-load catalyst efficiently utilized.

Similarly, it can be seen from Fig. 2 (b) that the performance of EOR has also been improved, from 413 $\mathrm{mA} \mathrm{mg}{ }^{-1} \mathrm{Pd}$ after $\mathrm{HCl}$ treatment to $546 \mathrm{~mA} \mathrm{mg}^{-1} \mathrm{Pd}$ after mixed acids treatment, with an increase rate of $32 \%$. This also reflected the increase in the utilization rate of $\mathrm{Pd}$ nanoparticles. For the same loading of $\mathrm{Pd}$, the performance of the foamed nickel electrode treated with mixed acid was higher.

Next, we assembled single cells to test the performance of nickel foam electrodes after different acid treatments in actual working environment. It can be seen from the cell polarization curve in Fig. 2 (c) that the maximum power density of the $\mathrm{HCl}$ treated electrode and the mixed acid treated electrode were $43 \mathrm{~mW} / \mathrm{cm}^{2}$ and $39 \mathrm{~mW} / \mathrm{cm}^{2}$ respectively, and the corresponding maximum current density at $0.1 \mathrm{~V}$ were both 320 $\mathrm{mA} / \mathrm{cm}^{2}$, and the open circuit voltage (OCV) were also not significantly different, respectively, $0.729 \mathrm{mV}$ and $0.749 \mathrm{mV}$. These cell performance parameters indicate that the two different acid treatment methods have negligible effects on the performance of the single cell. In order to further analyse the contribution of the cathode and anode electrodes to the cell voltage loss, we used SCE as the reference electrode to divide the cell voltage into two parts, the cathode potential and the anode potential. As shown in Fig. 2 (d), it can be found that the anode electrode potential loss of $\mathrm{HCl}$ treatment and mixed acid treatment were $400 \mathrm{mV}$ and $395 \mathrm{mV}$, respectively, and the difference between the values was very small and can be ignored.

However, this conclusion was inconsistent with the half-cell test results, so we think the possible reason is that in the three-electrode system, the Pd catalyst is used only at the microgram level, so the rough framework 
increases the active sites exposed by the catalyst and the catalyst is efficiently used; When preparing the single cell electrode, the amount of $\mathrm{Pd}$ catalyst is at the microgram level, a high amount of catalyst will completely cover the nickel foam skeleton and form a layer on the surface, which leads to the unused advantage of the rough skeleton. Therefore, the pretreatment method of nickel foam has little effect on the single cell performance.

\section{Conclusion}

This article mainly explores the effects of conventional $\mathrm{HCl}$ treatment and mixed acid treatment of nickel foam on the performance of alkaline direct ethanol fuel cells. The SEM images of the nickel foam surface of the two treatment methods were first observed. There were many small pores on the surface of the nickel foam treated with mixed acids, and the skeleton of the $\mathrm{HCl}$ treatment was smooth. In the following EOR half-cell and ethanol single cell test, some inconsistent conclusions were obtained. The performance of electrode made of nickel foam after mixed acids etching has been significantly improved in the half-cell test, while the impact on the performance of the full-cell was almost negligible. Due to the small amount of Pd used in half-cell electrode and the large amount of catalyst used in full-cell electrode, we believe the possible reason is that in the threeelectrode system, the $\mathrm{Pd}$ catalyst is used only at the microgram level, so the rough framework increases the active sites exposed by the catalyst and the catalyst is efficiently used. When preparing the single cell electrode, the amount of Pd catalyst is at the milligram level, a high amount of catalyst will completely cover the nickel foam skeleton and form a layer on the surface, which leads to the unused advantage of the rough skeleton. Therefore, the pretreatment method of nickel foam has little effect on the single cell performance.

\section{Acknowledgements}

The work described in this paper was fully supported by Grants from the NSFC, China (No. 51676092, No. 21676126), a Grant from the China Postdoctoral Science Foundation (No.2015M571685), Six-Talent-Peaks Project in Jiangsu Province (2016-XNY-015), High-Tech Research Key Laboratory of Zhenjiang City (No. SS2018002), and a Project Funded by the Priority Academic Program Development of Jiangsu Higher Education Institutions (PAPD), China.

\section{References}

1. L. An, T.S. Zhao, Y .S. Li, Renew. Sust. Energ. Rev. 50, 1462-8 (2015)

2. L. An, T.S. Zhao, J. Power Sources. 341, 199-211 (2017)

3. D.M. Fadzillah, S.K. Kamarudin, M.A. Zainoodin, M.S. M asdar, Int. J. Hydrog. Energy. 44, 3031-54 (2019)

4. N. Ramaswamy, S. Mukerjee, Chem Rev. 119, 11945-79 (2019)

5. W.C. Tan, L.H. Saw, H.S. Thiam, J. Xuan, Z. Cai, M.C. Y ew, Renew. Sust. Energ. Rev. 96, 181-97 (2018)

6. Y . Li, Y. He, RSC Adv. 4, 16879-84 (2014)

7. X. Niu, H. Zhao, M. Lan, J. Power Sources. 306, 361-8 (2016)

8. K. Xia, C. Y ang, Y. Chen, L. Tian, Y. Su, J. W ang, et al., Sens. A ctuators B Chem. 240, 979-87 (2017)

9. M. Grden, M. A lsabet, G. Jerkiewicz, ACS A ppl. $M$ ater. Interfaces. 4, 3012-21 (2012)

10. C. Zhang, C.F. Li, G.R. Li, J. Electrochemistry. 25, 571-578 (2019)

11. X. Sun, Y. Li, M.J. Li, ACS Sustain. Chem. Eng. 7, 11186-93 (2019)

12. H. Hou, S. W ang, W. Jin, Q. Jiang, L. Sun, L. Jiang, et al., Int. J. Hydrog. Energy. 36, 5104-9 (2011)

13. J. Zhang, P. Leung, F. Qiao, L. Xing, C. Y ang, H. Su, Q. Xu, Int. J. Hydrog. Energy. 45, 19801-12 (2020)

14. F.A. Zakil, S.K. Kamarudin, S. Basri, Renew. Sust. Energ. Rev. 65, 841-52 (2016)

15. Z. Zakaria, S.K. Kamarudin, S.N. Timmiati, A ppl. Energy. 163, 334-42 (2016)

16. L. Ma, D. Chu, R.R. Chen, Int. J. Hydrog. Energy. 37, 11185-94 (2012) 